\title{
A new technique for the solution of references problem in oil pollution measurement by UVF technique
}

\author{
Kasım C. Guven ${ }^{1}{ }^{*}$, Esra Billur Balcıoğlu ${ }^{2}$, Bayram Ozturk ${ }^{1}$ and Burak Coban ${ }^{3}$ \\ ${ }^{1}$ Turkish Marine Research Foundation (TUDAV), P.O. Box: 10, Beykoz, Istanbul, Turkey \\ ${ }^{2}$ Faculty of Fisheries, Istanbul University, Istanbul, Turkey \\ ${ }^{3}$ Department of Chemistry, Faculty of Arts and Sciences, Bulent Ecevit University, Zonguldak, Turkey
}

\begin{abstract}
In this work, the problems of references used for oil pollution measurement by UVF method were discussed. The main problem of this method is that the origin of the reference for pollutant oil is unknown. The proposed solution for this problem was based on sea water sample which was taken from contaminated area, extracted by DCM, the organic phase was distilled, its calibration curve was plotted with this residue oil and measurement was made on its equation. The oil pollution results for the sea water of $\mathrm{K}_{0}$ station by using this equation for 2013 was $15.21 \mathrm{mg} / \mathrm{L}$ and for $201415.25 \mathrm{mg} / \mathrm{L}$. for the same samples determination of oil pollution by using crude oil references varies between 0.11 and 1.15 various crude oils and using chrysene reference 0.11 $0.19 \mathrm{mg} / \mathrm{L}$. These results show that pollution level varied depending on references used. The proposed method more realistically determines the oil pollution level. The proposed technique is the first for oil pollution measurement by UVF.
\end{abstract}

Keywords: UVF, references, sea water, chrysene, extracted oil.

\section{Introduction}

Oil pollution is an important problem in the sea water for the coastal countries while it is a big risk for the marine life. Various methods were used for the measurement of oil pollution in sea water such as Ultra violet fluorescence (UVF), GC/MS, HPLC and MS. Among these, UV fluorescence spectroscopy is a rapid and cheap screening technique but it can be applied only to pure compounds. Some errors may arise from the conditions as oil pollution is measured such as the temperature of the sea water and time of the pollution which affect microbial degradation and photo-oxidation. Their degradation products fluorescence intensity is lower than their parent hydrocarbons. Another important point is the reference material used as crude oil type for the calibration material which influences the result of the measurement for UVF application because of the dissimilarity of fluorescence intensity of crude oil references which varies depending on the origin of the crude oil. Another deficiency of the UVF method is that the crude oil which is likely to be used or transported in the area of investigation is not really known. . Because of this reason, chrysene which is a polycyclic hydrocarbon and a natural constituent of crude oil was recommended to be used as a reference by UNESCO ${ }^{1}$. However; this solution has some disadvantages such as variability of chrysene amount in different crude oil samples and variability of chrysene fluorescence intensity depending on the chosen wavelength. Thus the results may be uncertain based on the reference used as discussed by several authors where each uses different reference oil depending on the country of origin and origin of the imported oil in the region or Chrysene ${ }^{2-}$ 13. However, there is no report on the solution of this problem.

In this work, a new technique was proposed for elimination of this problem in determining oil pollution by UVF analysis.

\section{Results and Discussion}

The results of oil pollution in examined stations calculated according to the calibration curves (shown in Fig 1) are shown in Table 1 and in Table 2 depending on various crude oils and chrysene references that the pollution levels vary depending on references used. In our earlier studies since 1991 in Bosphorus and other parts of Turkish Coasts oil pollution levels were examined and found that they differ depending on the references. 

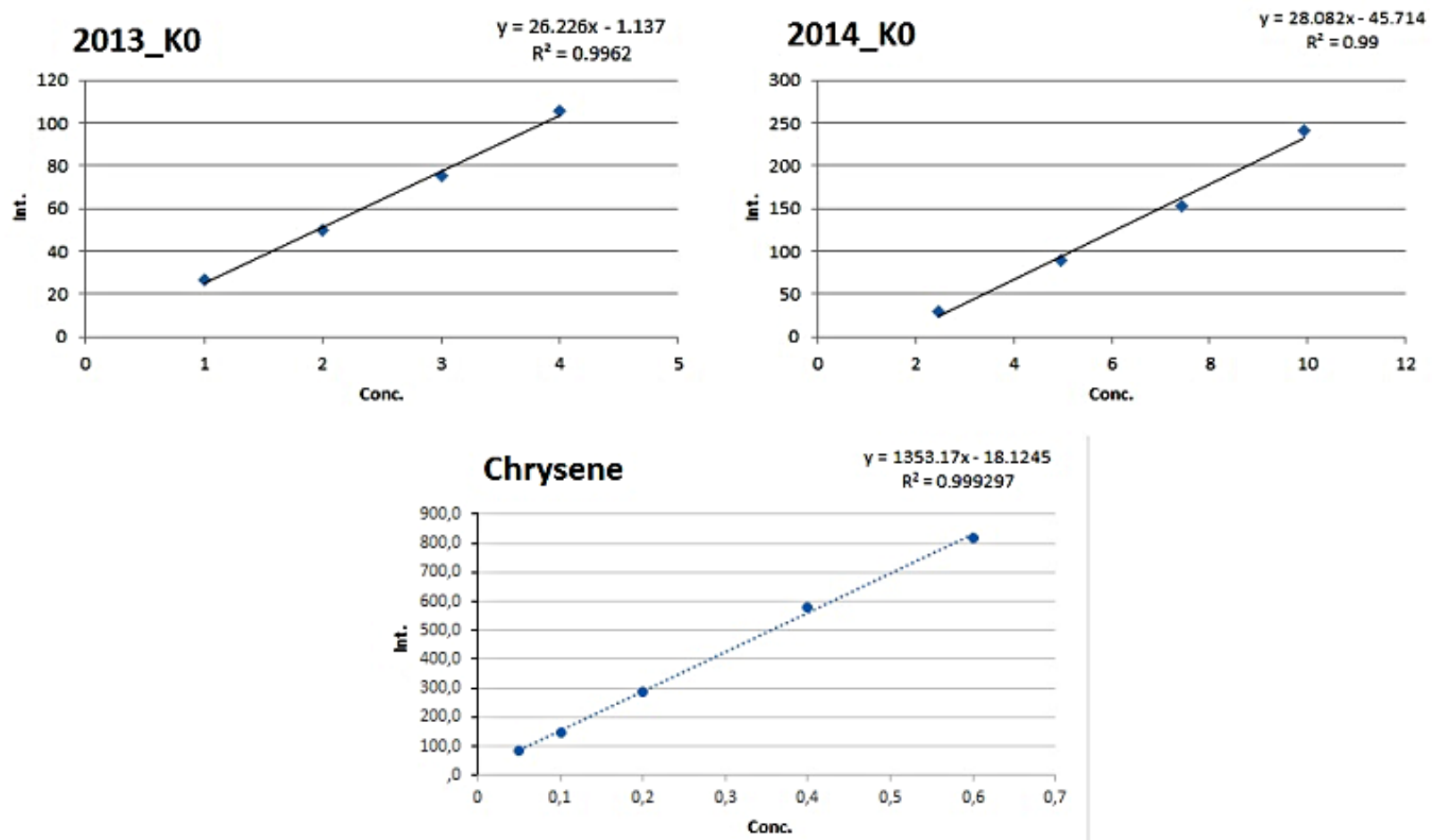

Figure 1. Calibration curves for chrysene and residue oil for $\mathrm{K}_{0}$ for 2013 and 2014.

Bosphorus is the only water-way for an exchange of Black Sea water in the straits acting as a funnel and collecting all types of pollution and oil from the rivers running into the Black Sea, including Danube, carrying into Aegean Sea ${ }^{14,15}$. In the same area, oil pollution was found varied monthly $\left(\mu \mathrm{g} \mathrm{ml}^{-}\right.$ $\left.{ }^{1}\right)$; $\mathrm{K}_{0}: 2.46-292.98$ in $2005,8.08-316.64$ in $2006, \mathrm{~K}_{0}$ : $13.51-169.9, \mathrm{~K}_{0 \mathrm{~A}}: 14.88-329.66, \mathrm{~K}_{0 \mathrm{~B}}: 17.4-112.78$ in 2007 and varied depending on the references 3.1328.63 Russian oil reference and 1.88-38.8 for chrysene reference ${ }^{12,15,16}$.
In this work Bosphorus entrance was chosen as the sample collection station because the Black Sea water flows through Bosphorus towards the Aegean Sea with various contaminants including oil etc ${ }^{17}$.

The problem of UVF analysis is that this measurement can only be applied in the areas where the origin of the oil is known. Otherwise the result obtained will be erroneous. In addition, it is difficult to adopt any single standard equation for this analysis.

Table 1a. The oil amounts $\left(\mu \mathrm{g} \mathrm{ml}^{-1}\right)$ at the stations calculated from the standard equations derived from the proposed technique using residue oil in 2013-2014.

\begin{tabular}{llll}
\hline \multirow{2}{*}{ Years } & \multicolumn{3}{c}{ Sampling stations } \\
& $\mathbf{K}_{\mathbf{0}}$ & $\mathbf{K}_{\mathbf{0 A}}$ & $\mathbf{K}_{\mathbf{0 B}}$ \\
\hline $\mathbf{2 0 1 3}$ & 15.21 & 13.36 & 18.45 \\
$\mathbf{2 0 1 4}$ & 15.25 & 10.41 & 10.27 \\
\hline
\end{tabular}

Table 1b. The comparison of the oil pollution $\left(\mu \mathrm{g} \mathrm{ml}{ }^{-1}\right)$ of the station $\mathrm{K}_{0}$ as a result of the use of various references in 2013-2014.

\begin{tabular}{lll}
\hline \multirow{2}{*}{ References } & \multicolumn{2}{c}{ Oil pollution at $\mathbf{K}_{\mathbf{0}}$} \\
& $\mathbf{2 0 1 3}$ & $\mathbf{2 0 1 4}$ \\
\hline Chrysene & 0.11 & 0.19 \\
Iran & 0.11 & 0.73 \\
Iraqi & 0.79 & 1.08 \\
Russian & 1.15 & 0.78 \\
\hline
\end{tabular}




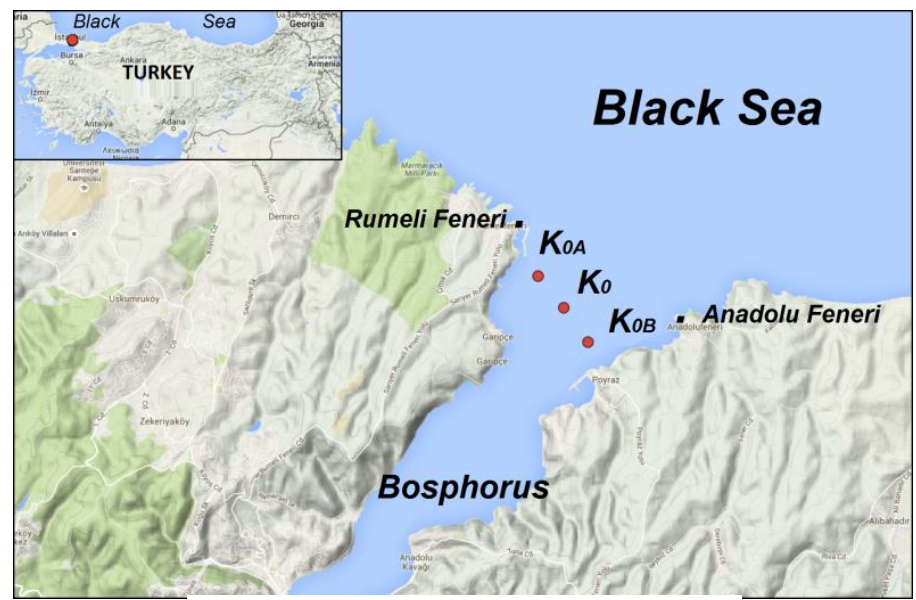

Figure 2. Location sites of the samples.

The determination of oil pollution is especially important in the Mediterranean and Black Sea countries where tanker traffic is dense and the origins of oil varied. The determination of oil pollution depending on the various reference oils (Russian, Iranian, and Iraqi) gave different results (table 1b) which are not reliable so there is a need to change the method. This new method to determine the "real" pollution values by using oil extracted from the sea water collected from the polluted area as the reference oil was proposed.

This study has also indicated that the local oil reference according to the proposed method has to be spatially and temporally prepared for the realistic measurement of the oil pollution.

\section{Conclusion}

The oil pollution of sea water has become a big problem in all countries. It is difficult to determine the exact pollution level by using a reference material of a crude oil or chrysene while the equation of the standard curve of each crude oil of different origin were not similar. Thus the results change depending of the origin. Even each country prefers the reference oil which was the most imported oil into the country; it is difficult to adopt any single standard equation. Accurate quantitative analysis by UVF is possible only where the sample and standard have the same aromatic composition. This is possible only if the sample collected during the matter of hours after an oil spill occurred as was indicated. No significant correlation was observed between the methods based on the neither crude oil nor chrysene references. Thus, a new method is proposed. In this method, the residue oil was used as reference which was extracted from the sea water taken from the polluted area.

In this proposed method the result will be more realistic for the determination of oil pollution.

\section{Experimental Section}

References: The residue oil obtained from polluted sea water; Chrysene (Aldrich, Belgium); Iranian, Iraqi and Russian crude oils imported by TUPRAŞ, İzmit, Turkey.

Apparatus: UVF Fluorospectrophotometer RF 5301 PC, Shimadzu.

Location site of seawater samples: Midpoint of entrance of Bosphorus $\left(\mathrm{K}_{0}\right), 500 \mathrm{~m}$ west side $\left(\mathrm{K}_{0 \mathrm{~A}}\right)$ and $500 \mathrm{~m}$ east side $\left(\mathrm{K}_{0 \mathrm{~B}}\right)$ are shown in Fig 2.

Sampling dates: Dec. 2013 and Dec. 2014.

Sample volume: $30 \mathrm{~L}$ for residue oil extraction and $3 \mathrm{~L}$ for oil pollution measurement.

Intensity measurement (ex/em): $310 / 360 \mathrm{~nm}$ for oil extracted from seawater and $310 / 374 \mathrm{~nm}$ for chrysene.

Solvents: Hexane, dichloromethane (DCM) (Merck, Darmstadt), anhydrous sodium sulphate (BASF).

Calibration curve for crude oil: concentrations between $0.25-1.5 \mu \mathrm{g} \mathrm{mL} \mathrm{m}^{-1}$ in hexane, 310/360 ex/em.

Calibration curve for chrysene: concentrations between $0.05-0.3 \mu \mathrm{g} \mathrm{mL} \mathrm{m}^{-1}$ in hexane, 270/390 ex/em.

Proposed method: Extraction of oil from the polluted area: Sea water samples were collected from the surface by a glass jar placed in a steel cage. The jar was cleaned with detergent and DCM prior to the collection of the samples. For calibration curve determination, sea water sample (30 L) was divided into $800 \mathrm{ml}$ portions and each was extracted with 3 x $30 \mathrm{~mL}$ DCM. Organic phases were combined in a weighted flask with a stopper on and distilled with a splash head on at 40 ${ }^{\circ} \mathrm{C}$. The residue reweighted and calibration curve was plotted in a concentration of $1.25-3.0 \mu \mathrm{g} \mathrm{mL}^{-1}$ in hexane.

Determination of oil pollution: Seawater sample (3 L) taken from each stations was extracted in a same manner as described above and the pollution level was measured by using each standard curve plotted for each station. 


\section{References}

1- UNESCO Manual for monitoring oil and dissolved/dispersed hydrocarbons in marine and on beaches. Manuals and Guides, 1984, No. 13. p. 13.

2- R. J. Law, Mar. Poll. Bull., 1981, 12, 153-157.

3- R. J. Law, M. Marchand, G. Dahlmann, T. W. Fileman, Mar. Poll. Bull., 1987, 18, 486-489.

4- M. Ehrhardt, G. Petrick, Mar. Poll. Bull., 1989, 20, 560-565.

5- M. Ehrhardt, G. Petrick, Mar. Chem., 1993, 42, 57-70.

6- M. Picer, V. Hocenski, Water Res., 1994, 28, 619629.

7- A. R. Abdullah, W. C. Woon, R. A. Bakar, Bull. Environ. Contam. Toxicol., 1996, 57, 155-162.

8- I. M. Madany, A. Jaffar, E. S. Al-Shirbini, Environ. Int., 1998, 24, 61-66.

9- N. Mazoughi, M. Dachraoui, J. P. Willeneuve, Comptes. Rendus Chimie, 2005, 8, 97-102.
10-B. Öztürk, K. C. Güven, F. Nesimigil, S. Cumal, A. Dede, J. Black Sea Mediterranean Environ., 2006, 12, 201-212.

11-11- K. C. Güven, F. Nesimigil, J. Black Sea Mediterranean Environ., 2008, 14, 119-127.

12- E. B. Balcıoğlu, B. Öztürk, J. Black Sea Mediterranean Environ., 2009, 15, 99-108

13-K. C. Güven, B. Coban, Acta Pharmaceutica Sciencia, 2011, 53, 635-638.

14-14- K. C. Güven, F. Nesimigil, S. Cumal1, J. Black Sea Mediterranean Environ., 2009, 15, 165-178.

15-K. C. Güven, B. Coban, Fres. Environ. Bull., 2012, 21, 3711-3717.

16- K. C. Güven, F. Nesimigil, S. Cumal, A. Yalçın, B. Coban, J. Black Sea Mediterranean Environ., 2010, 16, 253-283.

17-K. C. Güven, B. Coban, H. Erdugan, Int. Res. J. Public. Environ. Health, 2015, 2,122-126. 